\title{
Frequency and Correlation of Body Mass Index and Waist-Hip Ratio with Fasting Glycemia and Blood Pressure in High School Students from Mexico
}

Lourdes Adriana Medina-Gaona, ${ }^{1}$ Nallely Enríquez-Sánchez, ${ }^{2}$ Carla Elizabeth Mejía-Ramírez,3 Nathalia de Jesús Orueta-Mondragón, ${ }^{4}$ Heriberto Medina-Franco,5 Yareri Sandoval-Morales, ${ }^{6}$ Tanya Plett-Torres.7

\begin{abstract}
Background: Overweight/obesity is a global public health problem in adolescents. Its frequency is increasing as similar to diabetes, hypertension, health expenses, and poor quality of life. Thus, detecting overweight/obesity early in life promises a positive impact on the world's health. Methods: In a crosssectional study, differences were explored between glycemia and blood pressure according to BMI, WHR, age, sex, number of daily meals and family history of chronic diseases in high school students from Mexico City. Results: The prevalence of overweight and obesity in the participants (115) was $26 \%$ and $7 \%$, respectively. Fasting glycemia (mg/dL) was higher in students aged 17 vs. .18 ( $91.45 \pm 7.96$ vs $87.59 \pm 10.06, p=0.038)$. All hyperglycemic students and with android adipose distribution were women. Compared to the other participants, overweight students had higher systolic (107.24 $\pm 12.31 \mathrm{vs}$ $115.73 \pm 15.28, \mathrm{p}=0.003$ ) and diastolic $(70.99 \pm 10.93 \mathrm{vs} 76.27 \pm 13.02, \mathrm{p}=0.033)$ mean values (mmHg). Systolic values were higher in obesity (108.77 $\pm 13.03 \mathrm{vs}$ $118.63 \pm 18.38, p=0.048)$. Men had a higher frequency of systolic $(32 \%, p=0.001)$ and diastolic $(37 \%, p=0.023)$ prehypertension/hypertension than women ( $8 \%$ and $17 \%$, respectively). Systolic prehypertension/hypertension was common in overweight (47\% vs $53 \%$, $p=0.008)$. Skipping meals was common in students with family history of hypertension ( $13 \%$ vs $87 \%, \mathrm{p}=0.005$ ). Conclusion: The prevalence of overweight was higher and of obesity was lower than the one reported in ENSANUT 2016 (22.4\% and $13.9 \%$, respectively). Sex differences in blood glucose and pressure were obtained: men had higher blood pressures and women with abdominal fat had higher fasting glycemia. Systolic blood pressure was higher in overweight and obesity.
\end{abstract}

Key Words: Body Mass Index, Waist-Hip Ratio, Blood glucose, Blood pressure, Students (Source: MeSH-NLM).

\begin{abstract}
Introduction
The prevalence of overweight and obesity in subjects 20 years old and older has significantly increased in the last decades in several countries..$^{1-2} \mathrm{~A}$ similar trend has been observed in Mexico together with the increase of associated morbidities.3-5 The presence of obesity in children and adolescents is related to impairment of glucose tolerance, insulin resistance, and development of type-2 diabetes (DM2) later in life. Also, those with prehypertension have a higher possibility to develop hypertension in adulthood, while abdominal adiposity has a positive association with insulin resistance, dyslipidemias, DM2, and hypertension in all age stages. ${ }^{6-15}$ Thus, describing anthropometric characteristics, fasting glycemia, and family history of obesity-related diseases early in life is useful to create intervention programs with significant impact on the subject's health and expenses in adulthood. ${ }^{16}$ 18 Our hypothesis was that students from a Mexican private high school with high Body Mass Index (BMI) and/or with high Waist-Hip Ratio (WHR) would have a significantly higher concentration of fasting blood glucose and blood pressure compared to students without the mentioned characteristics.
\end{abstract}

The aim of our study was to obtain the frequency and correlation of demographic, anthropometric (BMI, WHR), family history of common diseases, and life-style characteristics with fasting glycemia and blood pressure of students of a Mexican private high school.

\section{Methods}

From February to March 2016, high school students from the Instituto Tecnológico y de Estudios Superiores de Monterrey (ITESM) in Mexico
City (CCM) were invited to carry out this exploratory cross-sectional study. Students were invited to participate through a brief informative presentation shown in different high-school classes by student investigators where selection criteria and the process of consent was explained, pointing out that participants should not have insulin resistance or diabetes, and that those interested in participating, should attend with 6-8 $\mathrm{h}$ fasting (only water intake was allowed) and without having exercised before measurements. Appointments were scheduled before students' classes (7 a.m. to 8 a.m.) and measurements were not made if students did not comply with the instructions for consent, fasting and exercise.

Adult students ( $\geq 18$ years) and parents of under-age participants signed a written informed consent in Spanish language. Under-age students also signed an informed assent. All students who agreed to participate (along with their parents' consent if they were minors) were included in the study. Those who reported insulin resistance, diabetes or with incomplete information were excluded. A printed self-applied questionnaire and all measurements were identified with the subject's number and were taken individually at the school's laboratory.

While they were sitting and after having obtained consent of the students, the participants answered a questionnaire that investigated the following characteristics: sex, age, weekly exercise, hours of exercise, number of daily meals, family history of cancer, cancer-type (classified as without cancer, 3 most common types, and not specified), overweight, obesity, insulin resistance and diabetes. When finished, blood pressure was measured with an electronic wrist sphygmomanometer (Citizen $\odot$ ). Then, capillary blood was taken using

\footnotetext{
${ }^{1}$ Medical student, Instituto Tecnológico y de Estudios Superiores de Monterrey Mexico City Campus, Mexico.

2 Biotechnology Engineering student, Instituto Tecnológico y de Estudios Superiores de Monterrey Mexico City Campus, Mexico.

Biomedical Engineering student, Instituto Tecnológico y de Estudios Superiores de Monterrey Mexico City Campus, Mexico.

${ }^{4}$ Languages student, Centro Universitario Anglo Americano, Cuernavaca Morelos, Mexico.

MD, Oncological Surgery, Surgery Department, Instituto Nacional de Ciencias Médicas y Nutrición "Salvador Zubirán" Mexico City, Mexico.

${ }^{6}$ Nutritionist, Masters student, Clinical Nutrition, Escuela de Dietética y Nutrición del Instituto de Seguridad y Servicios Sociales de los Trabajadores del Estado, Mexico City, Mexico.

7 Pharmaceutical Biological Chemist, MSc, PhD, Head of teaching of the MD/PhD program, Faculty of Medicine, Universidad Nacional Autónoma de México, Mexico City, Mexico.

About the Author: Lourdes Adriana Medina Gaona is currently a third-year medical student of Instituto Tecnológico y de Estudios Superiores de Monterrey (ITESM) in Mexico City of a total of seven-year program. She is also a recipient of Honorific Mention given by ITESM in 2016. 
a sterile lancet to measure 6 to 8 -hour fasting glycemia with a digital glucometer (Accu-check ${ }_{\circledR}$ Roche $($ )). At the end of the session, anthropometric measures were taken in a private section of the laboratory. Student's hip and waist circumference was measured with an anthropometric measuring tape (Fiberglass (c)). Weight (kg) and height $(\mathrm{cm})$ were measured with a scale (Cientifica Vela Quin $®)$ ). The results were recorded by the student investigator in a section of the questionnaire.

Body Mass Index (BMI) was calculated with the formula: weight $(\mathrm{kg}) /$ height $^{2}\left(\mathrm{~m}^{2}\right)$. Waist-Hip Ratio (WHR) was calculated with the formula: waist $(\mathrm{cm}) /$ hip $(\mathrm{cm})$. Overweight and obesity were obtained according to the World Health Organization growth reference for 5 to 19 years (Overweight: BMI median +1 SD according to age, Obesity: BMI median+2 SD according to age), and classified and analyzed separately. 41 Adipose distribution according to WHR was classified as gynoid or android (gynoid: women $<0.8$ and men <1.0, android: women $\geq 0.8$ and men $\geq 1.0$ ). 19 Glycemia was categorized as normal (70 to 100 $\mathrm{mg} / \mathrm{dL}$ ) and hyperglycemia ( $>100 \mathrm{mg} / \mathrm{dL}$ ). ${ }^{20}$ Adults' blood pressure was classified according to the JNC7 values for systolic blood pressure as normotensive $<120 \mathrm{mmHg}$ and prehypertensive/hypertensive $\geq 120$ $\mathrm{mmHg}$, and for diastolic blood pressure as normotensive $<80 \mathrm{mmHg}$ and prehypertensive/hypertensive $\geq 80 \mathrm{mmHg}$. Blood pressure of underage students was classified as normotensive for those with systolic and/or diastolic blood pressure $<90^{\text {th }}$ percentile and prehypertensive/ hypertensive with values greater than the $90^{\text {th }}$ percentile, both according to sex, age and height.21

The database was constructed in Microsoft Excel ${ }^{\circledR}$ and analyzed in STATA 11 (StataCorp, TX)®. Parameters including mean, standard deviation, median, minimum and maximum quartiles, and skewness were calculated. Mean comparison test (t-test) was used to explore significant differences from zero between groups of variables with normal distribution and Kruskal-Wallis test was used to compare differences between groups of variables with non-normal distribution. Fisher's exact test was performed to compare proportions. Statistical significance was considered with $p$ value $<0.05$. The post-project registration ID in the ITESM Clinical Research Ethics Committee is DOFIOO.

\section{Results}

Table 1 shows the summary of the continuous variables of 115 participants. The mean age of the students was $17.43 \pm 1.13$ years, height $164.90 \pm 8.12 \mathrm{~cm}$, hip circumference $97.95 \pm 7.67 \mathrm{~cm}$, fasting glycemia $88.93 \pm 9.53 \mathrm{mg} / \mathrm{dL}$, systolic and diastolic blood pressure $109.45 \pm 13.60$ $\mathrm{mmHg}$ and $72.36 \pm 11.68 \mathrm{mmHg}$, respectively, and WHR of $0.81 \pm 0.06$. The median of weight was $60($ p25 55, p75 69) kg, waist circumference 78 (p25 73, p75 83) cm, weekly exercise 1 (p25 1, p75 1.5) hour and BMI 22 (p25 20, p75 24) kg/m². Women had significantly lower ( $p<0.001$ in all cases) mean height $(160.96 \pm 5.43 \mathrm{~cm}$ vs $172.3 \pm 7.15 \mathrm{~cm})$, systolic pressure $(106.01 \pm 12.29 \mathrm{mmHg}$ vs $115.9 \pm 13.74 \mathrm{mmHg}$ ) and WHR $(0.79 \pm 0.05$ vs $0.84 \pm 0.05)$, median weight ( $57 ;$ p25 51, p75 $64 \mathrm{~kg}$ vs 67.65 ; p25 60, p75 $78 \mathrm{~kg}$ ) and waist circumference (77; p25 70, p75 $82 \mathrm{~cm}$, vs 81; p25 76.5, p75 $88 \mathrm{~cm}, p=0.001)$ than men. There were no significant differences between the median weight $(\mathrm{kg})$ of men in our study and the one reported by the World Health Organization (WHO) (67.65 vs 67, $p=0.749)$ for the age range of the participants. The same was observed for the median weight of women ( 57 vs $56, p=0.154$ ) and for median $\operatorname{BMI}\left(\mathrm{kg} / \mathrm{m}^{2}\right)$ : $\operatorname{men}(23$ vs $21.5, p=0.081$ ) and women (22 vs $21.1, p=0.165) .41$

Table 1. Summary of quantitative characteristics of 115 students that participated in the study

\begin{tabular}{|c|c|c|c|c|c|}
\hline Characteristic & \multicolumn{2}{|c|}{ All participants } & Men & Women & $p$-value ${ }^{d}$ \\
\hline Normal distribution & Mean \pm SD & Skewness & Mean \pm SD & Mean \pm SD & \\
\hline Age (years) & $17.43 \pm 1.13$ & -0.89 & $17.65 \pm 1.00$ & $17.31 \pm 1.19$ & 0.122 \\
\hline Height $(\mathrm{cm})$ & $164.90 \pm 8.12$ & 0.29 & $172.3 \pm 7.15$ & $160.96 \pm 5.43$ & $<0.001$ \\
\hline $\operatorname{Hip}(\mathrm{cm})$ & $97.95 \pm 7.67$ & 0.61 & $99.13 \pm 7.48$ & $97.32 \pm 7.48$ & 0.231 \\
\hline Fasting glycemia (mg/dL) & $88.93 \pm 9.53$ & -0.46 & $88.68 \pm 7.52$ & $89.07 \pm 10.49$ & 0.835 \\
\hline \multicolumn{6}{|l|}{ Blood pressure (mmHg) } \\
\hline Systolic & $109.45 \pm 13.60$ & 0.79 & $115.9 \pm 13.74$ & $106.01 \pm 12.29$ & $<0.001$ \\
\hline Diastolic & $72.36 \pm 11.68$ & 0.37 & $74.95 \pm 11.76$ & $70.98 \pm 11.45$ & 0.083 \\
\hline WHR & $0.81 \pm 0.06$ & 0.48 & $0.84 \pm 0.05$ & $0.79 \pm 0.05$ & $<0.001$ \\
\hline Non-normal distribution & $\operatorname{Median}(\min , \max )^{b}$ & Skewness & $\operatorname{Median}(\min , \max )^{b}$ & $\operatorname{Median}(\min , \max )^{b}$ & $p^{e}$ \\
\hline Weight (kg) & $60(55,69)$ & 1.18 & $67.65(60,78)$ & $57(51,64)$ & $<0.001$ \\
\hline Waist (cm) & $78(73,83)$ & 1.16 & $81(76.5,88)$ & $77(70,82)$ & 0.001 \\
\hline Exercise (h) & $1(1,1.5)$ & 1.96 & $1(0,1.5)$ & $1(1,1.5)$ & 0.593 \\
\hline $\mathrm{BMI}\left(\mathrm{kg} / \mathrm{m}^{2}\right)$ & $22(20,24)$ & 1.4 & $23(21,25.5)$ & $22(20,24)$ & 0.336 \\
\hline
\end{tabular}

Legend: SD: Standard Deviation, BMI: Body Mass Index, WHR: Waist-Hip Ratio, ${ }^{b} 25^{\text {th }}$ percentile $=p 25,75^{\text {th }}$ percentile $=p 75,{ }^{d} p$ value for Student's $t$ test, ${ }^{e} p$ value for Kruskal-Wallis equality of populations rank test.

The distribution of subjects and their categorized characteristics according to sex is shown in Table 2. Regarding all participants, there was a higher participation of women $(75 / 115 ; 65 \%)$ than men $(40 / 115$; $35 \%$ ). Most students had normal fasting glycemia (107/115; 93\%), systolic $(96 / 115 ; 83 \%)$ and diastolic blood pressure values $(87 / 115$; $76 \%$ ). The frequency overweight was $26 \%(30 / 115)$ and of obesity $7 \%$ $(8 / 115)$. Family history of cancer was common $(63 / 115 ; 55 \%)$, being breast cancer the most frequent $(14 / 115 ; 12 \%)$. Family history of insulin resistance $(41 / 115 ; 36 \%)$, diabetes $(76 / 115 ; 66 \%)$, hypertension $(61 / 115$; $53 \%)$ or overweight/obesity $(81 / 115 ; 70 \%)$ was common. According to sex, significant differences were found. All students with hyperglycemia (8) and all with android adipose distribution (33) were women ( $p=0.049$ and $p<0.001$, respectively). Conversely, men had significantly higher prehypertension/hypertension systolic $(13 / 40 ; 32 \%)$ and diastolic (15/40; 37\%) frequencies ( $p=0.001$ and $p=0.023$, respectively) and of obesity $(4 / 40 ; 10 \%, p=0.446$, not significant). There were no significant differences for age $(p=0.538)$, overweight $(p=0.510)$, and obesity $(p=0.446)$.

Table 3 shows the distribution of subjects according to obesity. The frequency of obesity in young participants ( $\leq 17$ years) was significantly higher $(7 / 8 ; 88 \%, p=0.002)$ than the older ones $(1 / 7 ; 12 \%)$. All students with obesity had normal glycemia ( $p>0.999)$ and some showed systolic $(3 / 8 ; 37 \%, p=0.125)$ and/or diastolic prehypertension/hypertension (3/8; $37 \%, p=0.401)$. Most obese students $(6 / 8 ; 75 \%, p>0.999)$ had gynoid adipose distribution, family history of cancer $(7 / 8 ; 88 \%, p=0.071)$, being breast the most common type $(2 / 8 ; 24 \%, p=0.746)$, without significant differences between groups. Family history of insulin resistance was significantly higher in obesity $(6 / 8 ; 75 \%, p=0.024)$, report of diabetes $(7 / 8 ; 88 \%, p=0.262)$, overweight or obesity $(6 / 8 ; 75 \%, p>0.999)$ but without statistical significance. 
Table 2. Distribution of the participants according to sex and the categorized characteristics

\begin{tabular}{|c|c|c|c|c|}
\hline $\begin{array}{l}\text { Characteristic } \\
\text { Age (years) }\end{array}$ & $\begin{array}{c}\text { All } \\
(n=115) \\
n(\%)\end{array}$ & $\begin{array}{c}\text { Men } \\
(n=40) \\
n(\%)\end{array}$ & $\begin{array}{c}\text { Women } \\
(n=75) \\
n(\%)\end{array}$ & $p^{d}$ \\
\hline$\leq 17$ & $40(35)$ & $12(30)$ & $28(37)$ & 0.538 \\
\hline$\geq_{18}$ & $75(65)$ & $28(70)$ & $47(63)$ & \\
\hline \multicolumn{5}{|c|}{ Fasting glycemia (mg/dL) } \\
\hline$\leq 100$ & $107(93)$ & $40(100)$ & $67(89)$ & 0.049 \\
\hline$\geq_{101}$ & $8(7)$ & $0(0)$ & $8(11)$ & \\
\hline \multicolumn{5}{|c|}{ Systolic blood pressure (mmHg) } \\
\hline Normal & $96(83)$ & $27(68)$ & $69(92)$ & 0.001 \\
\hline $\begin{array}{l}\text { Prehypertension/ } \\
\text { Hypertension }\end{array}$ & $19(17)$ & $13(32)$ & $6(8)$ & \\
\hline \multicolumn{5}{|c|}{ Diastolic blood pressure ( $\mathrm{mmHg}$ ) } \\
\hline Normal & $87(76)$ & $25(63)$ & $62(83)$ & 0.023 \\
\hline $\begin{array}{l}\text { Prehypertension/ } \\
\text { Hypertension }\end{array}$ & $28(24)$ & $15(37)$ & $13(17)$ & \\
\hline \multicolumn{5}{|l|}{ Overweight ${ }^{\mathrm{a}}$} \\
\hline No & $85(74)$ & $28(70)$ & $57(76)$ & 0.51 \\
\hline Yes & $30(26)$ & $12(30)$ & $18(24)$ & \\
\hline \multicolumn{5}{|l|}{ Obesity ${ }^{0}$} \\
\hline No & 107 (93) & $36(90)$ & 71 (95) & 0.446 \\
\hline Yes & $8(7)$ & $4(10)$ & $4(5)$ & \\
\hline \multicolumn{5}{|l|}{ WHRC } \\
\hline Gynoid & $82(71)$ & $40(100)$ & $42(56)$ & $<0.001$ \\
\hline Android & $33(29)$ & $0(0)$ & $33(44)$ & \\
\hline \multicolumn{5}{|c|}{ Family history of cancer } \\
\hline No & $52(45)$ & $21(52)$ & $31(41)$ & 0.326 \\
\hline Yes & $63(55)$ & $19(48)$ & $44(59)$ & \\
\hline \multicolumn{5}{|c|}{ Family history of cancer type } \\
\hline None & $52(45)$ & $15(37)$ & $37(50)$ & 0.325 \\
\hline Breast & $14(12)$ & $7(18)$ & $7(9)$ & \\
\hline Lung & $7(6)$ & $2(5)$ & $5(7)$ & \\
\hline Pancreas & $4(4)$ & $3(7)$ & $1(1)$ & \\
\hline Other & $36(31)$ & $12(30)$ & $24(32)$ & \\
\hline Not specified & $2(2)$ & $1(3)$ & $1(1)$ & \\
\hline \multicolumn{5}{|c|}{ Family history of insulin resistance } \\
\hline No & $74(64)$ & $26(65)$ & $48(64)$ & $>0.999$ \\
\hline Yes & $41(36)$ & $14(35)$ & $27(36)$ & \\
\hline \multicolumn{5}{|c|}{ Family history of diabetes } \\
\hline No & $39(34)$ & $11(27)$ & $28(37)$ & 0.31 \\
\hline Yes & $76(66)$ & $29(73)$ & $47(63)$ & \\
\hline \multicolumn{5}{|c|}{ Family history of hypertension } \\
\hline No & $54(47)$ & $18(45)$ & $36(48)$ & 0.845 \\
\hline Yes & $61(53)$ & $22(55)$ & $39(52)$ & \\
\hline \multicolumn{5}{|c|}{ Family history of overweight and/or obesity } \\
\hline No & $34(30)$ & $13(32)$ & $21(28)$ & 0.67 \\
\hline Yes & $81(70)$ & $27(68)$ & $54(72)$ & \\
\hline
\end{tabular}

Legend: aBMI: median+1SD according to age, ${ }^{\mathrm{B}} \mathrm{BMI}$ median+2SD according to age, 'Gynoid: women $<0.8$ and men $<1.0$, Android: women $\geq 0.8$ and men $\geq 1.0$, d $p$ value for Fisher's exact test.

The difference of fasting glycemia mean values between groups is shown in Table 4 . Students $\leq 17$ years had significantly higher mean values $(91.45 \pm 7.96 \mathrm{mg} / \mathrm{dL}, p=0.038)$ than older ones $(87.59 \pm 10.06$ $\mathrm{mg} / \mathrm{dL})$. Sex $(p=0.835)$, overweight $(p=0.491)$, obesity $(p=0.892)$ and WHR ( $p=0.201)$ did not show significant differences between groups.
Table 3. Distribution of the student's characteristics and obesity

\begin{tabular}{|c|c|c|c|}
\hline \multirow{2}{*}{ Characteristic (115) } & \multicolumn{2}{|c|}{ Obesity b } & \multirow{2}{*}{$p^{d}$} \\
\hline & No (107) & Yes (8) & \\
\hline & $\mathrm{n}(\%)$ & $\mathrm{n}(\%)$ & \\
\hline \multicolumn{4}{|l|}{ Age (years) } \\
\hline$\leq_{17}(40)$ & $33(31)$ & $7(88)$ & \multirow[t]{2}{*}{0.002} \\
\hline$\geq_{18}(75)$ & $74(69)$ & $1(12)$ & \\
\hline \multicolumn{4}{|l|}{ Fasting glycemia $(\mathrm{mg} / \mathrm{dL})$} \\
\hline$\leq_{100}(107)$ & $99(93)$ & $8(100)$ & \multirow[t]{2}{*}{$>0.99$} \\
\hline$\geq_{101}(8)$ & $8(7)$ & $0(0)$ & \\
\hline \multicolumn{4}{|l|}{ Systolic blood pressure ( $\mathrm{mmHg}$ ) } \\
\hline Normal (96) & $91(85)$ & $5(63)$ & \multirow[t]{2}{*}{0.125} \\
\hline Prehypertension/Hypertension (19) & $16(15)$ & $3(37)$ & \\
\hline \multicolumn{4}{|l|}{ Diastolic blood pressure $(\mathrm{mmHg})$} \\
\hline Normal (87) & $82(77)$ & $5(63)$ & \multirow[t]{2}{*}{0.401} \\
\hline Prehypertension/Hypertension (28) & $25(23)$ & $3(37)$ & \\
\hline \multicolumn{4}{|l|}{ WHR } \\
\hline Gynoid (82) & $76(7)$ & $6(75)$ & \multirow[t]{2}{*}{$>0.999$} \\
\hline Android (33) & $31(29)$ & $2(25)$ & \\
\hline \multicolumn{4}{|l|}{ Family history of cancer } \\
\hline No $(52)$ & $51(48)$ & $1(12)$ & \multirow[t]{2}{*}{0.071} \\
\hline Yes $(63)$ & $56(52)$ & $7(88)$ & \\
\hline \multicolumn{4}{|l|}{ Family history of cancer type } \\
\hline None (52) & $49(46)$ & $3(38)$ & \multirow[t]{6}{*}{0.746} \\
\hline Breast (14) & $12(11)$ & $2(24)$ & \\
\hline Lung (7) & $7(6)$ & $0(0)$ & \\
\hline Pancreas (4) & $4(4)$ & $0(0)$ & \\
\hline Other (36) & $33(31)$ & $3(38)$ & \\
\hline Not specified (2) & $2(2)$ & $0(0)$ & \\
\hline \multicolumn{4}{|l|}{ Family history of insulin resistance } \\
\hline No $(74)$ & $72(67)$ & $2(25)$ & \multirow[t]{2}{*}{0.024} \\
\hline Yes (41) & $35(33)$ & $6(75)$ & \\
\hline \multicolumn{4}{|l|}{ Family history of diabetes } \\
\hline No (39) & $38(36)$ & $1(12)$ & \multirow[t]{2}{*}{0.262} \\
\hline Yes $(76)$ & $69(64)$ & $7(88)$ & \\
\hline \multicolumn{4}{|l|}{ Family history of hypertension } \\
\hline No (54) & $50(47)$ & $4(50)$ & \multirow[t]{2}{*}{$>0.999$} \\
\hline Yes $(61)$ & $57(53)$ & $4(50)$ & \\
\hline \multicolumn{4}{|l|}{$\begin{array}{l}\text { Family history of overweight and/or } \\
\text { obesity }\end{array}$} \\
\hline No $(34)$ & $32(30)$ & $2(25)$ & \multirow[t]{2}{*}{$>0.999$} \\
\hline Yes (81) & $75(70)$ & $6(75)$ & \\
\hline
\end{tabular}

Legend: ${ }^{b}$ BMI median+2SD according to age, ${ }^{c}$ Gynoid: women $<0.8$ and men <1.0, Android: women $\geq 0.8$ and men $\geq 1.0,{ }^{d} p$ value for Fisher's exact test.

All hyperglycemic students were women ( $p=0.049$ ) (Table 5). The prevalence of android adipose distribution of hyperglycemic students was significantly higher $(6 / 8 ; 75 \%, p=0.007)$ than gynoid adipose distribution $(2 / 8 ; 25 \%)$. Other variables did not show significant differences between groups.

The summary of students' blood pressure is shown in Table 6. No significant differences were found between mean blood pressure and age (systolic $p=0.628$ and diastolic $p=0.392$ ). Overweight students had significantly higher mean systolic $(115.73 \pm 15.28 \mathrm{mmHg}, p=0.003)$ and diastolic blood pressure $(76.27 \pm 13.02 \mathrm{mmHg}, p=0.033)$ than the rest of the participants $(107.24 \pm 12.31 \mathrm{mmHg}, 70.99 \pm 10.93 \mathrm{mmHg}$, respectively). The mean of systolic pressure $(\mathrm{mmHg})$ was significantly higher in obese students (108.77 \pm 13.03 vs $118.63 \pm 18.38 p=0.048)$ and no significant differences were found for diastolic values $(p=0.210)$. Students with 
gynoid adipose distribution had significantly higher systolic blood pressure $(111.59 \pm 14.67 \mathrm{mmHg}, p=0.008)$ than those with android adipose distribution $(104.15 \pm 8.63 \mathrm{mmHg}$ ). A same trend was observed in Table 7; the prevalence overweight (10/19; 53\%) or gynoid adipose distribution $(18 / 19 ; 95 \%)$ was significantly higher in those with systolic prehypertension/hypertension ( $p=0.008$ and $p=0.012$, respectively). The other variables explored had no significant differences between groups.

The distribution of students according to the number of daily meals is shown in Table 8 . Most students reported having $\geq 3$ daily meals $(100 / 115 ; 87 \%)$. Among students that skipped meals, the higher frequency was found in women $(13 / 15 ; 87 \%, p=0.082)$, in normoglycemic participants $(14 / 15 ; 93 \%, p>0.999)$, in those with normal systolic and diastolic pressure (14/15;93\%, $p=0.459$ and $12 / 15 ; 80 \%$, p>0.999, respectively), in those without overweight $(12 / 15 ; 80 \%$, $p=0.756)$ or who were not obese $(14 / 15 ; 93 \%, p>0.999)$ and in those with gynoid adipose distribution $(9 / 15 ; 60 \%, p=0.361)$. All these differences were not significant. Also, the higher frequency of students that skipped meals was found in those with family history of cancer (10/15; $67 \%, p=0.409)$, diabetes $(12 / 15 ; 80 \%, p=0.259)$, overweight/obesity (10/15; $67 \%, p=0.765)$, and was significant for hypertension ( $13 / 15 ; 87 \%, p=0.005)$.

\section{Discussion}

The aim of our study was to describe and correlate the demographic and anthropometric characteristics of the participants. Similar information has been analyzed worldwide where the description of the frequency and tendency of the increase of high BMI has been useful to justify prevention programs in youngsters.8,13,15 The increase in the prevalence of overweight and obesity has been registered from 1999 to 2016 in Mexican teenagers (between 12 and 19 years old) from general population.3-4 In 2016, the combined prevalence of overweight and obesity reached $36.3 \%$. In this report, the prevalence of overweight was $22.4 \%$ (women $26.4 \%$ and men $19.6 \%$ ) and for obesity was $13.9 \%$ (women $12.8 \%$ and men 14.5\%).5 According to our results (Table 2), the prevalence of overweight students was higher $(30 / 115 ; 26 \%, p=0.172)$ and for obesity was significantly lower $(8 / 115 ; 7 \%, p=0.016)$ than the reported for teenagers in 2016 (data not in table). Men showed a higher frequency of both parameters than women, being the prevalence of overweight significantly higher $(12 / 40 ; 30 \%, p=0.049)$ than the one of 2016; obesity was less frequent, but without statistical significance ( $4 / 40 ; 10 \%, p=0.219$, data not in table). In contrast, the prevalence of overweight and obesity in women was higher in 2016 (26.4\% and 12.8\%)

Table 4. Distribution of the student's characteristics and the fasting glycemia

\begin{tabular}{|c|c|c|}
\hline \multirow[t]{2}{*}{ Characteristic } & \multicolumn{2}{|c|}{ Fasting glycemia (mg/dL) } \\
\hline & $\mathrm{Mean}_{ \pm} \mathrm{SD}$ & $p^{d}$ \\
\hline \multicolumn{3}{|l|}{ Age (years) } \\
\hline$\leq 17$ & $91.45 \pm 7.96$ & 0.038 \\
\hline$\geq_{18}$ & $87.59 \pm 10.06$ & \\
\hline \multicolumn{3}{|l|}{ Sex } \\
\hline Male & $88.68 \pm 7.52$ & 0.835 \\
\hline Female & $89.07 \pm 10.49$ & \\
\hline \multicolumn{3}{|l|}{ Overweight ${ }^{\mathrm{a}}$} \\
\hline No & $88.56 \pm 9.65$ & 0.491 \\
\hline Yes & $89.97 \pm 9.28$ & \\
\hline \multicolumn{3}{|l|}{ Obesity ${ }^{b}$} \\
\hline No & $88.90 \pm 9.64$ & 0.892 \\
\hline Yes & $89.38 \pm 8.48$ & \\
\hline \multicolumn{3}{|l|}{ WHR } \\
\hline Gynoid & $88.21 \pm 8.78$ & 0.201 \\
\hline Android & $90.73 \pm 11.14$ & \\
\hline
\end{tabular}

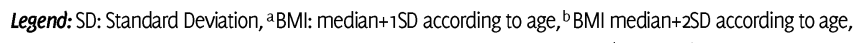
'Cynoid: women $<0.8$ and men $<1.0$, Android: women $\geq 0.8$ and men $\geq 1.0,{ }^{d} p$ value for Student's t test.
Table 5. Categorized fasting glycemia and the characteristics of the participants

\begin{tabular}{|c|c|c|c|}
\hline \multirow[b]{2}{*}{ Characteristic (115) } & \multicolumn{3}{|c|}{ Fasting glycemia $(\mathrm{mg} / \mathrm{dL})$} \\
\hline & $\begin{array}{c}\leq 100 \\
(n=107)\end{array}$ & $\begin{array}{l}\geq 101 \\
(n=8)\end{array}$ & $p^{d}$ \\
\hline & $\mathrm{n}(\%)$ & $\mathrm{n}(\%)$ & \\
\hline \multicolumn{4}{|l|}{ Age (years) } \\
\hline$\leq_{17}(40)$ & $36(34)$ & $4(50)$ & \multirow[t]{2}{*}{0.446} \\
\hline$\geq_{18}(75)$ & (66) & $4(50)$ & \\
\hline \multicolumn{4}{|l|}{ Sex } \\
\hline Male (40) & $40(37)$ & $0(0)$ & \multirow[t]{2}{*}{0.049} \\
\hline Female (75) & $67(63)$ & $8(100)$ & \\
\hline \multicolumn{4}{|l|}{ Systolic pressure $(\mathrm{mmHg})$} \\
\hline Normal (96) & $89(83)$ & $7(88)$ & \multirow[t]{2}{*}{$>0.99$} \\
\hline Prehypertension/Hypertension (19) & $18(17)$ & $1(13)$ & \\
\hline \multicolumn{4}{|l|}{ Diastolic pressure $(\mathrm{mmHg})$} \\
\hline Normal $(87)$ & $80(75)$ & $7(88)$ & \multirow[t]{2}{*}{0.677} \\
\hline Prehypertension/Hypertension (28) & $27(25)$ & $1(12)$ & \\
\hline \multicolumn{4}{|l|}{ Overweight ${ }^{2}$} \\
\hline No $(85)$ & $78(73)$ & $7(88)$ & \multirow[t]{2}{*}{0.678} \\
\hline Yes (30) & $29(27)$ & $1(12)$ & \\
\hline \multicolumn{4}{|l|}{ Obesity ${ }^{b}$} \\
\hline No (107) & $99(93)$ & $8(100)$ & \multirow[t]{2}{*}{$>0.99$} \\
\hline Yes (8) & $8(7)$ & $0(0)$ & \\
\hline \multicolumn{4}{|l|}{$W^{C} R^{C}$} \\
\hline Gynoid (82) & $80(75)$ & $2(25)$ & \multirow[t]{2}{*}{0.007} \\
\hline Android (33) & $27(25)$ & $6(75)$ & \\
\hline \multicolumn{4}{|l|}{ Family history of cancer } \\
\hline No (52) & $50(47)$ & $2(25)$ & \multirow[t]{2}{*}{0.29} \\
\hline $\operatorname{Yes}(63)$ & $57(53)$ & $6(75)$ & \\
\hline \multicolumn{4}{|l|}{ Family history of cancer type } \\
\hline None (52) & $49(46)$ & $3(37)$ & \multirow[t]{6}{*}{0.593} \\
\hline Breast (14) & $12(11)$ & $2(25)$ & \\
\hline Lung (7) & $6(5)$ & $1(13)$ & \\
\hline Pancreas (4) & $4(4)$ & $0(0)$ & \\
\hline Other (36) & $34(32)$ & $2(25)$ & \\
\hline Not specified (2) & $2(2)$ & $0(0)$ & \\
\hline \multicolumn{4}{|l|}{ Family history of insulin resistance } \\
\hline No (74) & $70(65)$ & $4(50)$ & \multirow[t]{2}{*}{0.453} \\
\hline Yes $(41)$ & $37(35)$ & $4(50)$ & \\
\hline \multicolumn{4}{|l|}{ Family history of diabetes } \\
\hline No (39) & $38(36)$ & $1(12)$ & \multirow[t]{2}{*}{0.262} \\
\hline Yes (76) & $69(64)$ & $7(88)$ & \\
\hline Family history of hypertension & & & \\
\hline No (54) & $50(47)$ & $4(50)$ & $>0.999$ \\
\hline Yes $(61)$ & $57(53)$ & $4(50)$ & \\
\hline Family history of overweight and/or 0 & & & \\
\hline No (34) & $33(31)$ & $1(13)$ & 0.433 \\
\hline Yes $(81)$ & $74(69)$ & $7(87)$ & \\
\hline
\end{tabular}

Legend: a BMI: median+1SD according to age, ${ }^{b} B M I$ median+2SD according to age, ' Cynoid: women $<0.8$ and men $<1.0$, Android: women $\geq 0.8$ and men $\geq_{1.0}$, ${ }^{d} p$ value for Fisher's exact test.

than in our study $(18 / 75 ; 24 \%$ and $4 / 75 ; 5 \%$, respectively), being significant for obesity ( $p=0.027$, data not in table). 5 Most obese students (Table 3 ) were $\leq 17$ years ( $7 / 8 ; 88 \%, p=0.002$ ), which represents a risk of early onset of insulin resistance. In high-income countries like the United States (U.S.), the risk of overweight in white adolescent girls increases as socioeconomic status decreases, whereas in black population the opposite occurs. 4 
Table 6. Summary of the student's blood pressure according to their characteristics

\begin{tabular}{|c|c|c|c|c|}
\hline \multirow[t]{2}{*}{ Characteristic } & \multicolumn{2}{|c|}{ Systolic (mmHg) } & \multicolumn{2}{|c|}{ Diastolic (mmHg) } \\
\hline & Mean \pm SD & $p^{d}$ & Mean \pm SD & $p^{d}$ \\
\hline \multicolumn{5}{|l|}{ Age (years) } \\
\hline$\leq 17$ & $110.3 \pm 16.93$ & 0.628 & $73.65 \pm 12.40$ & 0.392 \\
\hline$\geq_{18}$ & $109.0 \pm 11.55$ & & $71.68 \pm 11.31$ & \\
\hline \multicolumn{5}{|l|}{ Overweight ${ }^{\mathrm{a}}$} \\
\hline No & $107.24 \pm 12.31$ & 0.003 & $70.99 \pm 10.93$ & 0.033 \\
\hline Yes & $115.73 \pm 15.28$ & & $76.27 \pm 13.02$ & \\
\hline \multicolumn{5}{|l|}{ Obesity $^{b}$} \\
\hline No & $108.77 \pm 13.03$ & 0.048 & $71.99 \pm 11.62$ & 0.21 \\
\hline Yes & $118.63 \pm 18.38$ & & $77.38 \pm 12.18$ & \\
\hline \multicolumn{5}{|l|}{$\mathrm{WHR}^{\mathrm{C}}$} \\
\hline Gynoid & $111.59 \pm 14.67$ & 0.008 & $73.65 \pm 12.08$ & 0.064 \\
\hline Android & $104.15 \pm 8.63$ & & $69.18 \pm 10.12$ & \\
\hline
\end{tabular}

Legend: SD: Standard Deviation, ${ }^{a} \mathrm{BMI}$ : median+1SD according to age, ${ }^{\mathrm{b}} \mathrm{BMI}$ median+2SD according to age, 'Gynoid: women $<0.8$ and men $<1.0$, Android: women $\geq 0.8$ and men $\geq 1.0,{ }^{d} p$ value for Student's t test.

In England and in other developed countries, white teenagers with less than median income, have a higher prevalence of overweight and obesity, a marked trend in girls. ${ }^{47-48}$ The correlation between high BM and socioeconomic status in developing countries is not clear; in those with low-income is positive for men and women and in middle-income countries de association is mixed for men and mainly negative for women. 37 The participants in our study belong to a socioeconomic group in Mexico that live in the city, is highly educated, with mediumhigh household income, and has access to health and food services. ${ }^{36}$ In Mexico, well-off adolescents (attending to private school, remunerated job, and mother's higher level of education) had a higher probability of overweight or obesity. ${ }^{38}$ Also, those that live in urban areas have a higher prevalence of overweight or obesity, being the latter more frequent in adolescents of the highest quintile of Household Living Condition Index (income per capita, literacy rate, and life expectancy).49 The higher frequency of overweight found in male participants in our study may reflect trend of this parameter in high income Mexican population.

We were unable to detect significant differences between glycemia and BMl: all students with obesity were normoglycemic (Table 3) and no significant differences between mean values of fasting glycemia and high BMI were found (Table 4). On the other hand, significant differences were found for sex (all students with hyperglycemia were women, $p=0.049$, Table 2) and age (mean values were significantly higher in participants $<=17$ years, $p=0.038$, Table 4$)$. Studies have reported no correlation between mean fasting glycemia in Mexican teenagers (between 12 and 15 years) and overweight or obesity. Other reports show a significant correlation of overweight and obesity and insulin resistance and with high systolic and diastolic blood pressure in Mexican adolescents. ${ }^{8}$ Students with obesity in our study had a significantly higher prevalence of family history of insulin resistance $(6 / 8 ; 75 \%, p=0.024)$, suggesting a trend of family unhealthy lifestyle or inherited biological risk factors. In relation to this, obesity is associated to breast, colon, endometrial, esophageal, gall bladder and renal cancer, mainly because of insulin resistance and $\mathrm{DM}_{2}$, events that produce chronic inflammation and tolerance, sustaining proliferative signals (through IGF-1 axis, leptin and adipokines) and low levels of glucagon and of adiponectin. $43-45$ Related to the above, we did not find a significant correlation between family history of cancer and student's obesity ( $p=0.071$, Table 3 ). Also, we did not explore BMI of the reported cases to analyze correlations, including those for the current student's BMI.

We observed that students with hyperglycemia had significantly higher frequency of android adipose distribution ( $p=0.007$, Table 5), confirming our hypothesis for high WHR. Women had significantly higher frequency of android adipose distribution $(44 \%, p<0.001)$ and all men had gynoid adipose distribution (Table 2 ). Android adipose distribution comprises excess fat in the upper body region (particularly in the abdomen) that has been associated to $\mathrm{DM} 2$, deficient cardiac mechanics, systolic dysfunction and hypertension. ${ }^{10-12}$ In teenagers from 9 to 17 years, android adipose distribution has been associated to dyslipidemia and systolic blood pressure. ${ }^{14}$ Thus, the hyperglycemic women with android adipose distribution found in our study may be at risk of developing $\mathrm{DM}_{2}$ and/or cardiovascular diseases in the future if not promptly treated. A contrasting result was that students with gynoid adipose distribution showed significantly higher $(p=0.008)$ systolic blood pressure than those with android adipose distribution (Table 6). It has been reported that in children and adolescents, the risk of hypertension may not be directly associated with BMI or WHR as in adults, instead, subscapular and triceps skinfold thickness could be more related to it. 46 In future studies, the distribution of body fat in teenagers should be measured also taking into account these parameters to compare them.

We encountered significant correlations between high BMI and high blood pressure. Overweight students had mean systolic and diastolic blood pressure significantly higher ( $p=0.003$ and $p=0.033$, respectively) than the rest of the participants (Table 6). Also, students with obesity, showed a significantly higher systolic mean value $(p=0.048)$ than the other participants. With categorized variables (Table 7), overweight students showed a significantly higher prevalence of systolic prehypertension/hypertension $(p=0.008)$. These students are at risk of maintaining high blood pressure values and reaching chronic diseases like hypertension in adulthood if their high BMI is not reduced with lifestyle changes, education and/or diet intervention. ${ }^{13}$ High BM accounts for 2.7 million deaths globally. ${ }^{2}$ obesity increases the risk of DM2, cancer and cardiovascular diseases in adolescence and adulthood.32-34 Prehypertension/high BMI in adolescence is linked to the development of hypertension 2 years later, being more frequent in boys $(68 \%)$ than in girls $(43 \%) .33$ Coincidently, we also found that male adolescents had a significantly higher frequency of systolic $(p=0.001)$ and diastolic prehypertension/ hypertension ( $p=0.023$ ) than women (Table 2). Hypertension is the most common comorbidity in overweight adolescents; each unit of increase of BMI is associated with a higher risk of systolic blood pressure $>130 \mathrm{mmHg} .{ }^{35}$ Factors like age, ethnicity, family history of hypertension and/or DM2, genetic polymorphisms, low birth weight, pubertal status, insufficient physical activity, poor sleep quality, reduced adiponectin, dyslipidemia and inappropriate sodium/ potassium intake are also positively associated to the development of hypertension in adulthood. 6 Reports show that the prevalence of prehypertension/hypertension in teenagers in the U.S. is around $10 \%$ and the trajectory of blood pressure appears to lag 10 years behind of BMI. ${ }^{1}$ Thus, interventions that reduce the incidence of overweight and obesity in teenagers may prevent the development of hypertension and cardiovascular complications as adults.

We evaluated weekly hours of exercise and number of daily meals as part of the students' habits. We found that participants practiced exercise ( $1 \mathrm{~h}$ median weekly exercise, Table 1 ) but there was no significant difference with any of the variables evaluated. It has been reported that interventions focused on practicing exercise, schoolhealth centers, healthy eating and food policies have a beneficial role in preventing overweight and obesity in school-age children and that would impact in adolescence. ${ }^{16-18}$ Most of the participants in our study $(100 / 115 ; 87 \%$ ) answered they had three meals per day (Table 8 ), but women had a higher frequency of skipping them, without significance $(p=0.082)$. We also found that $40 \%(6 / 15)$ of the participants that skipped meals had android adipose distribution and all of them were women. Skipping meals and snacking have become frequent; a difficult distinction between typical breakfast, lunch and dinner has emerged.24 The prevalence of skipping meals in adults varies from 5 to $83 \%$, being males more likely to skip any meal and women to skip lunch and dinner. ${ }^{23}$ Conversely, as we found in our study, adolescent girls have a higher frequency of skipping any meal and men tend to skip breakfast and lunch and, in general, breakfast is the meal least consumed.23,25-27 This behavior has an impact of the quality of the ingested food and in the subject's health; the odds of skipping meals decreases the daily consumption of healthy food and increases the consumption of junk 
food (fat-rich), leading to increase the waist circumference and to develop metabolic alterations. ${ }^{27,30}$ As a consequence, skipping breakfast has been associated with increased prevalence of obesity, android adipose distribution, dyslipidemia, hyperinsulinemia and hyperglycemia. ${ }^{24-25,28-29}$ Even though healthy lifestyle considers the consumption of breakfast, lunch and dinner as main meals, ( 1 to 3 snacks between them), skipping them is a common practice wrongly considered a way to reduce energy intake (lose weight). ${ }^{31}$ on the other hand, family history of hypertension was more frequent students that skipped meals $(13 / 15 ; 87 \%, p=0.005)$. In this sense, skipping meals, especially breakfast, is related increased adiposity indicators and it is related to metabolic changes that predispose the development of chronic diseases. ${ }^{26}$ Eating in misalignment with the biological clock (skipping breakfast and consuming copious meals in the evening or eating late at night) has long-term effects as developing metabolic syndrome, increased risk of obesity, DM2 and coronary heart disease. ${ }^{31,40}$
We are aware of the limitations of our exploratory cross-sectional study: no causality can be inferred, we included all students that voluntarily agreed to participate (self-selection of the population and low sample size) and they don't represent all high school students or adolescents in Mexico. They are a subgroup of private school students with different characteristics from the general population. We could have measured glycosylated hemoglobin to obtain a more accurate approach of glucose metabolism. Also, the measurement of weekly exercise could have been more effective with a smartphone application (widely used by youngsters) as it has been reported for walkability inequality. ${ }^{22}$ Likewise; we need of a more detailed description of daily meals (type and snacks) of the participants. Another point is that family reports rely on the student's memory and certain bias may be experienced (close relatives are remembered better than distant ones and the participant's age may influence the report). All these observations could have been adjusted if the questionnaire validation had been carried out.

Table 7. Distribution of the high school students according to their blood pressure and other characteristics

\begin{tabular}{|c|c|c|c|c|c|c|}
\hline \multirow{2}{*}{$\begin{array}{l}\text { Characteristic } \\
(n=115)\end{array}$} & \multicolumn{3}{|c|}{ Systolic (mmHg) } & \multicolumn{3}{|c|}{ Diastolic (mmHg) } \\
\hline & Normal $(n=96)$ & Prehypertension/hypertension ( $n=19$ ) & $p^{d}$ & Normal $(n=87)$ & Prehypertension/hypertension $(n=28)$ & $p^{d}$ \\
\hline & $\mathrm{n}(\%)$ & $\mathrm{n}(\%)$ & & $\mathrm{n}(\%)$ & $\mathrm{n}(\%)$ & \\
\hline \multicolumn{7}{|l|}{ Age (years) } \\
\hline$\leq_{17}(40)$ & $34(35)$ & $6(32)$ & 0.799 & $31(36)$ & $9(32)$ & 0.822 \\
\hline$\geq_{18}(75)$ & $62(65)$ & $13(68)$ & & $56(64)$ & $19(68)$ & \\
\hline \multicolumn{7}{|l|}{ Overweight ${ }^{\mathrm{a}}$} \\
\hline No (85) & $76(79)$ & $9(47)$ & 0.008 & $68(78)$ & $17(61)$ & 0.085 \\
\hline Yes (30) & $20(21)$ & $10(53)$ & & $19(22)$ & $11(39)$ & \\
\hline \multicolumn{7}{|l|}{ WHR } \\
\hline Gynoid (82) & $64(67)$ & $18(95)$ & 0.012 & $59(68)$ & $23(82)$ & 0.229 \\
\hline Android (33) & $32(33)$ & $1(5)$ & & $28(32)$ & $5(18)$ & \\
\hline \multicolumn{7}{|c|}{ Family history of cancer } \\
\hline No $(52)$ & $46(48)$ & $6(32)$ & 0.217 & $38(43)$ & $14(52)$ & 0.509 \\
\hline Yes $(63)$ & $50(52)$ & $13(68)$ & & $50(57)$ & $13(48)$ & \\
\hline \multicolumn{7}{|c|}{ Family history of cancer type } \\
\hline None $(52)$ & $43(45)$ & $9(48)$ & 0.682 & $41(47)$ & $11(39)$ & 0.787 \\
\hline Breast (14) & $11(12)$ & $3(16)$ & & $10(12)$ & $4(14)$ & \\
\hline Lung (7) & $6(6)$ & $1(5)$ & & $4(5)$ & $3(11)$ & \\
\hline Pancreas (4) & $4(4)$ & $0(0)$ & & $3(3)$ & $1(4)$ & \\
\hline Other (36) & $31(32)$ & $5(26)$ & & $27(31)$ & $9(32)$ & \\
\hline Not specified (2) & $1(1)$ & $1(5)$ & & $2(2)$ & $0(0)$ & \\
\hline \multicolumn{7}{|c|}{ Family history of insulin resistance } \\
\hline No $(74)$ & $64(67)$ & $10(53)$ & 0.297 & $55(63)$ & $19(68)$ & 0.821 \\
\hline Yes $(41)$ & $32(33)$ & $9(47)$ & & $32(37)$ & $9(32)$ & \\
\hline \multicolumn{7}{|c|}{ Family history of diabetes } \\
\hline No (39) & $34(35)$ & $5(26)$ & 0.598 & $30(34)$ & $9(32)$ & $>0.999$ \\
\hline Yes (76) & $62(65)$ & $14(74)$ & & $57(66)$ & $19(68)$ & \\
\hline \multicolumn{7}{|c|}{ Family history of hypertension } \\
\hline No $(54)$ & $46(48)$ & $8(42)$ & 0.802 & $42(48)$ & $12(43)$ & 0.668 \\
\hline Yes (61) & $50(52)$ & $11(58)$ & & $45(52)$ & $16(57)$ & \\
\hline \multicolumn{7}{|c|}{ Family history of overweight and/or obesity } \\
\hline No (34) & $30(31)$ & $4(21)$ & 0.426 & $28(32)$ & $6(21)$ & 0.346 \\
\hline Yes (81) & $66(69)$ & $15(79)$ & & $59(68)$ & $22(79)$ & \\
\hline
\end{tabular}

Legend: aBMI: median+1SD according to age, ${ }^{b B M I}$ median+2SD according to age, 'Cynoid: women $<0.8$ and men $<1.0$, Android: women $\geq 0.8$ and men $\geq 1.0,{ }^{d} p$ value for Fisher's exact test. 
Table 8. Distribution of the student's characteristics and number of daily meals

\begin{tabular}{|c|c|c|c|}
\hline Characteristic (115) & $<3$ meals $(n=15)$ & $\geq_{3}$ meals $(n=100)$ & $p^{d}$ \\
\hline & $\mathrm{n}(\%)$ & $\mathrm{n}(\%)$ & \\
\hline \multicolumn{4}{|l|}{ Age (years) } \\
\hline & $5(33)$ & $35(35)$ & \multirow[t]{2}{*}{$>0.999$} \\
\hline$\geq_{18}(75)$ & $10(67)$ & $65(65)$ & \\
\hline \multicolumn{4}{|l|}{ Sex } \\
\hline Male (40) & $2(13)$ & $38(38)$ & \multirow[t]{2}{*}{0.082} \\
\hline Female (75) & $13(87)$ & $62(62)$ & \\
\hline \multicolumn{4}{|c|}{ Fasting glycemia (mg/dL) } \\
\hline$\leq_{100}(107)$ & $14(93)$ & $93(93)$ & \multirow[t]{2}{*}{$>0.999$} \\
\hline$\geq_{101}(8)$ & $1(7)$ & $7(7)$ & \\
\hline \multicolumn{4}{|c|}{ Systolic blood pressure (mmHg) } \\
\hline Normal (96) & $14(93)$ & $82(82)$ & \multirow[t]{2}{*}{0.459} \\
\hline $\begin{array}{l}\text { Prehypertension/ } \\
\text { Hypertension (19) }\end{array}$ & $1(7)$ & $18(18)$ & \\
\hline \multicolumn{4}{|c|}{ Diastolic blood pressure (mmHg) } \\
\hline Normal (87) & $12(80)$ & $75(75)$ & \multirow[t]{2}{*}{$>0.999$} \\
\hline $\begin{array}{l}\text { Prehypertension/ } \\
\text { Hypertension (18) }\end{array}$ & $3(20)$ & $25(25)$ & \\
\hline \multicolumn{4}{|l|}{ Overweight ${ }^{\mathrm{a}}$} \\
\hline No (85) & $12(80)$ & $73(73)$ & \multirow[t]{2}{*}{0.756} \\
\hline Yes (30) & $3(20)$ & $27(27)$ & \\
\hline \multicolumn{4}{|l|}{ Obesity $^{b}$} \\
\hline No $(107)$ & $14(93)$ & $93(93)$ & \multirow[t]{2}{*}{$>0.999$} \\
\hline Yes (8) & $1(7)$ & $7(7)$ & \\
\hline \multicolumn{4}{|l|}{ WHR $^{c}$} \\
\hline Gynoid (82) & $9(60)$ & $73(73)$ & \multirow[t]{2}{*}{0.361} \\
\hline Android (33) & $6(40)$ & $27(27)$ & \\
\hline \multicolumn{4}{|c|}{ Family history of cancer } \\
\hline No $(52)$ & $5(33)$ & $47(47)$ & \multirow[t]{2}{*}{0.409} \\
\hline Yes (63) & $10(67)$ & $53(53)$ & \\
\hline \multicolumn{4}{|c|}{ Family history of cancer type } \\
\hline None (52) & $6(40)$ & $46(46)$ & \multirow[t]{6}{*}{0.685} \\
\hline Breast (14) & $1(7)$ & $13(13)$ & \\
\hline Lung (7) & $2(13)$ & $5(5)$ & \\
\hline Pancreas (4) & $0(0)$ & $4(4)$ & \\
\hline Other (36) & $6(40)$ & $30(30)$ & \\
\hline Not specified (2) & $0(0)$ & $2(2)$ & \\
\hline \multicolumn{4}{|c|}{ Family history of insulin resistance } \\
\hline No (74) & $10(67)$ & $64(64)$ & \multirow[t]{2}{*}{$>0.999$} \\
\hline Yes (41) & $5(33)$ & $36(36)$ & \\
\hline \multicolumn{4}{|c|}{ Family history of diabetes } \\
\hline No (39) & $3(20)$ & $36(36)$ & 0.259 \\
\hline Yes (76) & $12(80)$ & $64(64)$ & \\
\hline Family history of hype & & & \\
\hline No $(54)$ & $2(13)$ & $52(52)$ & 0.005 \\
\hline Yes (61) & $13(87)$ & $48(48)$ & \\
\hline Family history of over & & & \\
\hline No $(34)$ & $5(33)$ & $29(29)$ & 0.765 \\
\hline Yes (81) & $10(67)$ & 71 (71) & \\
\hline
\end{tabular}

Legend: a BMI: median+1SD according to age, ${ }^{\mathrm{b}}$ BMI median+2SD according to age, ${ }^{c}$ Cynoid: women $<0.8$ and men $<1.0$, Android: women $\geq 0.8$ and men $\geq 1.0,{ }^{d} p$ value for Fisher's exact test. 
We conclude that, the participants of this study, specifically male students, had a higher prevalence of overweight than the one of general population with the same age range. In contrast, the prevalence of obesity in the studied population was lower than the one reported for general population. Participants showed a correlation of overweight and obesity with high blood pressure, especially men. On the other hand, the group of younger students showed higher fasting glycemia, especially women when android adipose distribution was present. Our findings reinforce the idea of creating a better intervention program than the current one in this high school (the current approach is to address related information in health class, with infographics about breakfast around the campus and Institute's on-line information) in order to reduce the number of overweight and obese students. ${ }^{2}$ Several interventions could be created focused on public health action, which implies changing the context of the students instead of only showing information about the risks of high BMI. An example would be reducing the availability of fat-rich food, salt or increasing vegetables in the menu of the school's cafeteria and in the products offered in vending machines placed all around the campus, together with the need to encourage students to consume healthier food. 39 The results of our study are helpful as they describe anthropometric parameters and markers of early onset of metabolic and cardiovascular diseases in a group of teenagers that has not been thoroughly studied. Thus, we recommend carrying out similar studies around the country (reducing the limitations of the present report) in order to create group-fitted health policies/programs nationwide. 


\section{References}

1. Tsujimoto T, Kajio H, Sugiyama T. Obesity, diabetes, and length of time in the United States: Analysis of National Health and Nutrition Examination Survey 1999 to 2012. Medicine (Baltimore). 2016; 95(35): e4578.

2. Collaborators GBDO, Afshin A, Forouzanfar MH, Reitsma MB, Sur P, Estep K, et al. Health Effects of Overweight and Obesity in 195 Countries over 25 Years. N Engl J Med. 2017; 377(1): 13-27.

3. Olaiz-Fernandez G, Rivera-Dommarco I, Shamah-Levy $T$, Rojas R, VillalpandoHernandez S, Hernandez-Avila M, et al. Encuesta Nacional de Salud y Nutricion 2006. 1st ed. Cuernavaca, Mexico: Instituto Nacional de Salud Publica; 2006. 132 p. 4. Cutierrez J, Rivera-Dommarco J, Shamah-Levy T, Villalpando-Hernandez S, Franco A, Cuevas-Nasu L, et al. [ENSANUT 2012: Analysis of its main results]. 1st ed. Cuernavaca, Mexico: Instituto Nacional de Salud Publica; 2012. 200 p.

5. Hernandez-Avila M, Rivera Dommarco I, Shamah-Levy T, Cuevas-Nasu L, Comez Acosta L, Gaona-Pineda E, et al. Encuesta Nacional de Salud y Nutricion de Medio Camino 2016. Instituto Nacional de Salud Publica; 2016.

6 . Kelly RK, Magnussen CG, Sabin MA, Cheung M, Juonala M. Development of hypertension

in overweight adolescents: a review. Adolesc Health Med Ther. 2015; 6: 171-87.

7. Sinha R, Fisch G, Teague B, Tamborlane WV, Banyas B, Allen K, et al. Prevalence of impaired glucose tolerance among children and adolescents with marked obesity. N Engl J Med. 2002; 346(11): 802-10.

8. Velasco-Martínez RM, Jiménez-Cruz A, Higuera Domínguez F, Domínguez de la Piedra E, Bacardí-Gascón M. [Obesity and insulin resistance among adolescents from Chiapas]. Nutr Hosp. 2009; 24(2): 187-92.

9. Eriksson JG, Osmond C, Kajantie E, Forsén TJ, Barker DJ. Patterns of growth among children who later develop type 2 diabetes or its risk factors. Diabetologia. 2006; 49(12): 2853-8.

10.Nkeh-Chungag BN, Mxhosa TH, Mgoduka PN. Association of waist and hip circumferences with the presence of hypertension and pre-hypertension in young South African adults. Afr Health Sci. 2015; 15(3): 908-16.

11. Russo C, Sera F, Jin Z, Palmieri V, Homma S, Rundek T, et al. Abdominal adiposity, general obesity, and subclinical systolic dysfunction in the elderly: A population-based cohort study. Eur I Heart Fail. 2016; 18(5): 537-44.

12. Selvaraj S, Martinez EE, Aguilar FG, Kim KY, Peng J, Sha J, et al. Association of Central Adiposity With Adverse Cardiac Mechanics: Findings From the Hypertension Genetic Epidemiology Network Study. Circ Cardiovasc Imaging. 2016; 9(6).

13. Urquidez Romero R, Murguía Romero M, Esparza Romero J, Díaz Torres BA, Rodríguez Tadeo A, Medrano Donlucas $G$, et al. Abdominal obesity is strongly associated to blood pressure in young Mexicans. Nutr Hosp. 2017:34(2):357-62.

14. Daniels SR, Morrison JA, Sprecher DL, Khoury P, Kimball TR. Association of body fat distribution and cardiovascular risk factors in children and adolescents. Circulation. 1999; 99(4): 541-5.

15. Salcedo-Rocha AL, de Alba JE, Contreras-Marmolejo M. [Classifying Mexican adolescents' high blood pressure, associated factors and importance]. Rev Salud Publica (Bogota). 2010; 12(4): 612-22.

16. Lakshman R, Elks CE, Ong KK. Childhood obesity. Circulation. 2012; 126(14): 1770-9. 17. Kong AS, Sussman AL, Yahne C, Skipper BJ, Burge MR, Davis SM. School-based health center intervention improves body mass index in overweight and obese adolescents. J Obes. 2013; 2013: 575016.

18. Hawkes C, Smith TC, Jewell I, Wardle J, Hammond RA, Friel S, et al. Smart food policies for obesity prevention. Lancet. 2015; 385(9985): 2410-21.

19. Obesity: preventing and managing the global epidemic. Report of a WHO consultation. World Health Organ Tech Rep Ser. 2000; 894: i-xii, 1-253.

20. Kaplan A, Jack R, Opheim K, Tiovola B, Lyon A. Clinical Chemistry: Interpretation and Techniques. 3rd ed. Malvern, PA: Williams at Wilkins; 1995. 514 p.

21. Anyaegbu El, Dharnidharka VR. Hypertension in the teenager. Pediatr Clin North Am. 2014; 61(1): 131-51.

22. Althoff T, Sosic R, Hicks JL, King AC, Delp SL, Leskovec J. Large-scale physical activity data reveal worldwide activity inequality. Nature. 2017; 547(7663): 336-9.

23. Pendergast FJ, Livingstone KM, Worsley A, McNaughton SA. Correlates of meal skipping in young adults: a systematic review. Int J Behav Nutr Phys Act. 2016; 13(1): 125. 24. St-Onge MP, Ard J, Baskin ML, Chiuve SE, Johnson HM, Kris-Etherton P, et al. Meal Timing and Frequency: Implications for Cardiovascular Disease Prevention: A Scientific Statement From the American Heart Association. Circulation. 2017; 135(9): eg6-e121. 25. Smith KJ, Gall SL, McNaughton SA, Blizzard L, Dwyer T, Venn AJ. Skipping breakfast: longitudinal associations with cardiometabolic risk factors in the Childhood Determinants of Adult Health Study. Am J Clin Nutr. 2010; 92(6): 1316-25.
26. Rodrigues P, Pereira R, Sebastião Santana A, Cama A, Carvalhal I, Nogueira H, et al. Irregular breakfast habits are associated with children's increased adiposity and children's and parents' lifestyle related behaviors: a population-based crosssectional study. Nutrire. 2016;41(8):1-10.

27. Kelishadi R, Mozafarian N, Qorbani M, Motlagh ME, Safiri S, Ardalan G, et al. Is snack consumption associated with meal skipping in children and adolescents? The CASPIANIV study. Eat Weight Disord. 2017; 22(2): 321-8.

28. Ma Y, Bertone ER, Stanek EJ, Reed CW, Hebert JR, Cohen NL, et al. Association between eating patterns and obesity in a free-living US adult population. Am Epidemiol. 2003; 158(1): 85-92.

29. Kobayashi F, Ogata H, Omi N, Nagasaka S, Yamaguchi S, Hibi M, et al. Effect of breakfast skipping on diurnal variation of energy metabolism and blood glucose. Obes Res Clin Pract. 2014; 8(3): e201-98.

30. Eloranta AM, Lindi V, Schwab U, Kiiskinen S, Venalainen T, Lakka HM, et al. Dietary factors associated with metabolic risk score in Finnish children aged 6-8 years: the PANIC study. Eur J Nutr. 2014; 53(6): 1431-9.

31. Wennberg M, Gustafsson PE, Wennberg P, Hammarstrom A. Irregular eating of meals in adolescence and the metabolic syndrome in adulthood: results from a 27-yea prospective cohort. Public Health Nutr. 2016; 19(4): 667-73.

32. Freedman DS, Dietz WH, Srinivasan SR, Berenson CS. The relation of overweight to cardiovascular risk factors among children and adolescents: the Bogalusa Heart Study. Pediatrics. 1999; $103(6$ Pt 1): 1175-82.

33. Assadi F. Prehypertension: a warning sign of future cardiovascular risk. Int J Prev Med. 2014; 5 (Suppl 1): S4-9.

34. Abdelaal M, le Roux CW, Docherty NG. Morbidity and mortality associated with obesity. Ann Transl Med. 2017; 5(7): 161

35.Debnath S. BMI is a Better Indicator of Cardiac Risk Factors, as against Elevated Blood Pressure in Apparently Healthy Female Adolescents and Young Adult Students: Results From a Cross-Sectional Study in Tripura. Indian J Community Med. 2016; 41(4): $292-8$. 36. Avila JL FC, Tuirán R. [Indices de marginación 2000]. First ed. Mexico: Consejo Nacional de Población; 2001. 49 p.

37. Dinsa GD, Coryakin Y, Fumagalli E, Suhrcke M. Obesity and socioeconomic status in developing countries: a systematic review. Obes Rev. 2012; 13(11): 1067-79.

38. Ortiz-Hernández L, Pérez-Salgado D, Tamez-Conzález S. [Socioeconomic inequality and health in Mexico]. Rev Med Inst Mex Seguro Soc. 2015; 53(3): 336-47.

39. Frieden TR. A framework for public health action: the health impact pyramid. Am Public Health. 2010; 100(4): 590-5.

40. Cahill LE, Chiuve SE, Mekary RA, Jensen MK, Flint AJ, Hu FB, et al. Prospective Study of Breakfast Eating and Incident Coronary Heart Disease in a Cohort of Male US Health Professionals Clinical Perspective. Circulation. 2013; 128(4): 337-43.

41. World Health Organization: Child growth standards. http://www.who.int. Accessed 15 May 2018.

42. Pontaza, D: [Breakfast as "king" can help you lose weight] https://tecreview.tec.mx/desayunar-rey-te-puede-ayudar-a-bajar-peso/ (2018). Accessed 18 May 2018

43. Stone TW, MCPherson M, Darlington LC. Obesity and Cancer: Existing and New Hypotheses for a Causal Connection. EBioMedicine. 2018

44. Prendergast CC, Metz R, Muller AJ. Towards a genetic definition of cancer-associated inflammation: role of the IDO pathway. The American journal of pathology. 2010;176(5):2082-7.

45. Hanahan D, Weinberg RA. Hallmarks of cancer: the next generation. cell. 2011;144(5):646-74.

46. Zhang Yx, Wang Sr. Distribution of subcutaneous fat and the relationship with blood pressure in obese children and adolescents in Shandong, China. Paediatric and perinatal epidemiology. 2015;29(2):156-61.

47. Wang Y, Beydoun MA. The obesity epidemic in the United States-gender, age socioeconomic, racial/ethnic, and geographic characteristics: a systematic review and meta-regression analysis. Epidemiologic reviews. 2007;29(1):6-28.

48. Stamatakis E, Wardle J, Cole TJ. Childhood obesity and overweight prevalence trends in England: evidence for growing socioeconomic disparities. International journal of obesity. 2010;34(1):41.

49. Hernández-Cordero S, Cuevas-Nasu L, Morales-Ruán M, Humarán IM-G, Ávila-Arcos $M$, Rivera-Dommarco J. Overweight and obesity in Mexican children and adolescents during the last 25 years. Nutrition at diabetes. 2017;7(2):e247.

\section{Acknowledgments}

We would like to thank ITESM CCM for letting us use its facilities to carry out this study. We would also like to thank Pharmaceutical Biological Chemist Isabel Coria Franco who is in charge of the Biology, Physics and Chemistry laboratories of ITESM CCM for her kind assistance and technical support and for lending us the school's equipment and supplies needed for the project. We also thank Veterinarian and full-time teacher at ITESM CCM Jorge Becerril Enriquez for letting us promote the project in all his classes, and for enthusiastically joining us to the massive invitation to participate in the study.

\section{Conflict of Interest Statement at Funding}

The Authors have no funding, financial relationships or conflicts of interest to disclose.

Author Contributions: Conception and design the work/idea: MGL, ESN, MRC, OMN. Collect data/obtaining results: MCL, ESN, MRC, OMN. Analysis and interpretation of data: MGL, ESN, MRC, OMN. Write the manuscript: MGL, ESN, MRC, PTT. Critical revision of the manuscript: MGL, ESN, MRC, MFH, SMY, PTT. Approval of the final version: MGL, ESN, MRC, OMN, SMY, PTT. Contribution of patients or study material: MGL, ESN, MRC, OMN. Statistical advice: MFH, PTT. Administrative or technical advice: PTT.

Cite as:

Medina-Gaona L, Enríquez-Sánchez N, Mejía- Ramírez C, Orueta-Mondragón N, Medina-Franco H, Sandoval-Morales Y, Plett-Torres T. Frequency and Correlation of Body Mass Index and Waist-Hip Ratio with Fasting Glycemia and Blood Pressure in High School Students from Mexico. Int J Med Students. 2018 MayAug;6(2):38-46.
} 